\title{
REGSPRAAK VOLGENS ARTIKEL 31 VAN DIE KERKORDE VAN DIE GKSA 'n Skriftuurlike beoordeling
}

\author{
M.A. Kruger \\ Departement Nuwe Testament \& Grieks \\ HTS / PU vir CHO \\ POTCHEFSTROOM
}

\begin{abstract}
Abstracl
Due to a number of reasons judicature in the Refonned Churches of South Africa (GKSA) has developed into a system which has been formed not so much by scriputral nonns as by other factors. Among these factors nere the influence of democracs; inadequate distinction between church government and church judicature, a dichotomy between the acceptance of norms for church judicature and so-called secular judicature, insufficient attention to biblical nonns and the development of a tradition among scholars of church law: Experience in phinan meetings of the church has indicated that church judicature' should be put on a sounder scriphural foundation.
\end{abstract}

\section{INLEIDING}

In die laaste artikel van die Kerkorde van die Gereformeerde Kerke in Suidelike Afrika (1979) word die moontlikheid en die noodsaaklikheid van verandering aan hierdie Kerkorde, indien nodig, gestel. Dis seker by uitstek nodig dat daar altyd gewaak sal word dat die Kerkorde nie 'n pad lángs die Skrif begin loop nie. Die kerk staan voortdurend voor die gevaar dat tradisie mettertyd die visie kan verblind en dat die Skrif sodoende verduister word. Daarom is dit veral die taak van Ou- en Nuwe-Testamentici en kerkregkundiges om te beoordeel of die Kerkorde beantwoord aan wat die Skrif eis.

Hierdie ondersoek gee aandag aan artikel 31 Kerkorde en in 'n volgende artikel sal aan artikels 72-76 gesamentlik aandag gegee word. Die keuse om aan hierdie artikels aandag te gee, is nie geïnspireer deur 'n verband tussen artikel 31 enersyds en artikels 72-76 andersyds nie, maar omdat dit uit die praktyk van die Gereformeerde kerklike lewe en op meerdere vergaderings geblyk het dat die toepassing van hierdie artikels in spanning staan met wat die Skrif eis ten opsigte van die handhawing van reg en ten opsigte van die onderlinge verbondsverantwoordelikheid wat die Skrif eis. 


\section{ARTIKEL 31}

\subsection{Die huidige bewoording van Artikel 31 Kerkorde}

Wat op 'n kerklike vergadering met mecrderheid van stemme besluit is, moet as vas en bindend beskou word tensy bewys word dat dit in stryd is met Gods Woord of dic artikcls van dic Kerkorde. As iemand egter 'n klagle hel dat hy deur dic uitspraak van die mindere vergadering verongelyk is, kan hy hom op 'n mecrdere vergadering berocp. (GKSA, 1979:3 c.v.)

\subsection{Die probleem}

Die probleem lê in die woorde "kan hy hom op 'n meerdere vergadering beroep". Sodra so 'n beroep plaasvind, appelleer die persoon en het daar 'n regsaak tot stand gekom. Wat in die mindere vergadering as 'n saak van kerkregering behandel is, verkry nou ' $n$ totaal ander aard, naamlik dié van 'n regsaak. Veral in die geval van persoonlike regskrenking word die regsaard van 'n appèl baie belangrik, maar dit kan ook in ander gevalle so wees waar dit gaan oor sake en nie persone nie.

\subsection{Vrae}

Onmiddellik kom 'n mens voor vrae te staan: kan 'n regsaak deur 'n regeringsliggaam behartig word? Is die samestelling van 'n regeringsliggaam sodanig dat dit regspraak kan beoefen? Is kerklike regeerders altyd gelyktydig ook mense wat die gawe van regspraak het? Kan daar werklik reg geskied in so 'n geval? Dis bekend hoedat by staatlike regerings juis ter wille van ware reg die wetgewende mag en die regspleging geskei word.

\subsection{Christus en regspraak}

Spoelstra (1989:191) sê by artikel 31 KO die volgende:

Die feit dat Jesus Christus die enigste Hoof van die kerk is (NGB 31), verg die hoogste integriteit, objektiwiteit en onpartydigheid van die vergadering wat 'n appèl moet behandel. Hulle is in besonder geroep om in diens van Christus reg te spreek asof Hy dit self doen. Die appellant doen immers ' $n$ beroep op dic reg wat dic Koning vir en in sy kerk voorgeskry' het. Die vergadering wat 'n appèl oorweeg, moet biddend met die reêle teenwoordigheid van Christus as Hoof van sy kerk en met die Gees rekening hou en God dien deur die waarhcid lief te hê. (Heid. Kat. S. 43.) 


\subsection{Regspraak in die Bybel}

Gispen (1960, 585-586) gee 'n goeie oorsig oor regspraak in die Bybel.

\subsubsection{Ou Testament}

In die eerste vyf boeke van die Bybel is daar verskeie uitsprake oor regspraak. Die regters oefen die reg uit manens God en word selfs gode genoem (Deut. 1:17 en Ps. $82: 1,6)$. In die patriargale tyd het die huisvader die regspraak behartig oor almal onder hom, byvoorbeeld soos in Genesis 38:24. Later, in Egipte het die oudstes waarskynlik reggespreek en daarna Moses. Uit Eksodus 18:13-27 en Deuteronomium 1:9-18 blyk dat Moses vir regsake van kleiner omvang regters uit die volk op aandrang van sy skoonvader Jetro aangestel het. Hierdie regters was hoofde oor duisend, oor honderd, oor vyftig en oor tien. In Numeri $25: 5$ is sprake van hierdie regters. Vir hoër beroep is gegaan na die priesters en Leviete (Deut. 17:8-13, vgl. 2 Kron. 19:8-11). In hierdie regsprekende liggaam was daar ook 'n regter wat nie van Levitiese of priesterlike afkoms was nie. Waarskynlik het die koning hierdie posisie beklee.

Die Rigters is ook deur die volk geraadpleeg om regsake te besleg (Rigters 4:5, 1 Samuel $7: 15-17,8: 1-3)$.

\section{Hoê cise vir regspraak in die Ou Testament}

In Deuteronomium 16:18-20 word 'n baie ernstige voorskrif aan die regters gegee:

Regters en opsiglers moet jy vir jou aanstel in al jou poorte wat dic HERE jou God jou sal gee volgens jou stamme; en hulle moct die volk oordecl volgens 'n regverdige regspraak. Jy mag dic reg nie verdraai nic; jy mag nic partydig wees nic; ook mag jy geen omkoopgeskenk aannecm nie, want die geskenk verblind die oé en verdraai die sake van die wat reg het. Geregligheid, geregligheid mocl jy najaag ...

Deur die vereiste dat daar ten minste twee getuies moes wees, is verder seker gemaak dat die reg werklik gehandhaaf sal word (Num. 35:30, Deut. 17:6, 19:15, Mat. 18:16). 'n Valse getuie moes streng gestraf word (Deut. 19:18-21).

\section{Gawes en verantwoordelikheid}

Regspraak is toevertrou aan manne wat bepaalde gawes besit het. Hulle moes onder andere betroubaar wees en onregverdige wins haat (Eks. 18:21). Ook moes hulle wyse, 
envare manne wees (Deut. 1:15), bekwaam vir die taak (Eks. 18:25), wys, verstandig en ervare wees (Deut. 1:13,15; vgl. 1 Korintiërs 6:5). Mense wat spesiaal afgesonder is vir die werk, spreek reg (Deut. 17:8,9). Die priesters het spesiaal opleiding gekry vir die regspraak en sommige was in staat om sake te behartig wat ander nie kon doen nie (Deut. 17:8-11).

'n Regter moes verantwoordelikheid dra vir sy regspraak want hy staan in die plek van God (vgl. Calvyn (1949) se verklaring van Ps 82:6) wanneer hy regspraak beoefen:

En hy het aan die regters gesê: Kyk wat julle doen, want julle spreck nie reg vir dic mens nic, maar vir die HERE; en Hy is by julle in dic regspraak. Mag die skrik vir die HERE dan nou op julle wees, handel nougeset, want by die HERE onse God is geen onreg of partydigheid of aanneming van geskenke nic. (2 Kron. 19:6, vgl. Deut. 1:17 en 16:20.)

\subsubsection{Nuwe Testament}

- Die norme van die Ou Testament aanvaar in die Nuwe Testament

In die Nuwe Testament word daar nie ander reëls gegee vir die regspraak nie. Kennelik moes dit wat in die Ou Testament voorgeskryf is, gehandhaaf bly. In 1 Korintiërs 6:5 is daar 'n eggo van Deuteronomium 1:13 as Paulus vra of hulle dan nie eers een wyse onder hulle het wat kan regspreek nie. Dit blyk ook hier duidelik dat burgerlike regspraak en kerklike regspraak nie geskei behoort te word nie. Eerder behoort dit so te wees dat wanneer gelowiges regsake onder mekaar het, hulle dit binne die kring van die gelowiges behoort op te los sonder om na die gewone burgerlike geregsinstansies te gaan. Verder is dit waarskynlik nie 'kerklike' sake waaroor dit hier gegaan het nie, maar 'burgerlike' sake. Oor kerklike sake sou buitestaanders tog nie kon uitspraak gee nie.

\section{- Dic Sanhedrin}

Die Sanhedrin kan nie genoem word as 'n voorbeeld van 'n liggaam wat reggespreek het nie. Ten eerste lees ons nie in die Ou Testament dat dit 'n liggaam vir regspraak is wat ingestel is op bevel van God nie. Ten tweede het die priesters, wat 'n vername deel van die Raad gevorm het, 'n heersende aristokrasie geword.

\section{5 .3 Samevatting}

Samevattend kan gestel word dat die volgende uit die Bybel duidelik word oor 
regspraak:

- Groot klem word daarop gelê dat onreg nie in die regspraak moet geskied nie.

- Regters tree op in die plek van God.

- Regters is opgeleide mense of mense wat besondere gawes het.

- Regspraak geskied nie deur 'n groot liggaam nie.

- 'n Regter moet verantwoordelikheid dra vir sy beslissing.

- Daar is nie 'n prinsipiële onderskeid tussen 'burgerlike' en 'kerklike' regspraak nie.

\subsection{Kerklike en burgerlike regspraak}

Daar word beweer dat bogenoemde norme nie van toepassing gemaak kan word op die kerklike erf nie, aangesien dit handel oor burgerlike regspraak (GKSA, 1988:136). Op grond van twee redes kan so 'n standpunt nie gehandhaaf word nie:

\section{- Skeiding tussen religieuse en sekulêre terreine}

Eerstens word deur hierdie bewering 'n skeiding tussen religieuse en sogenaamde sekulêre terreine gemaak wat nooit in die Ou Testament gemaak is nie. Vanuit 'n verworde siening word vandag dikwels 'n skeiding gemaak tussen die religieuse en die sogenaamde sekulêre lewe. Dit druis egter direk in teen die Calvinistiese opvatting dat alle terreine aan die Here gewy moet wees.

\section{- Skeiding tussen norme vir religieuse en sekulêre regspraak}

Tweedens misken hierdie skeiding tussen norme vir kerklike en burgerlike regspraak die feit dat God die norme gee vir regspraak en dat Hy nie twee stelle norme gee nie, maar net een. Eloff (1988:86) skryf dit is

duidelik dat die voorkoms van die vorme van sdq nic gronde gee om skeiding te maak tussen Goddelike en menslike geregtigheid nie. God se gercgtigheid is 'n aktiwiteit wat Hy in die lewe van die volk vitoefen (Ps. 9:5, Jes. 33:5), maar dis ook iets wat Hy van die volk eis (Jes. 5:7, Jer. 23:5). So staan $s d q$ binne die verbondsraamwerk ... Menslike geregtigheid is egter nie net religieus (in die sin van 'n regte verhouding met God) nie - dic geintegreerdheid van die Hebreeuse samelewing mak so 'n skeiding onmoontlik ...

Omdat God die Geregtige is, is Hy die Bron van en Norm vir alle menslike geregtigheid (Eloff, 1988:87). Veral Deuteronomium fundeer die reg religieus (Eloff, 1988:91). Herzberg (1923:18-19) stel die volgende oor die religieuse fundering van alle 
reg in Deuteronomium:

... von den Propheten an liess es sich mit Sicherheit nachweisen, dass " $\mathrm{b}$ mit Jahwe in Bezichung gebracht wird, ja, dass es als Ausdruck des Willens Jahwes erscheint; - dic Deuteronomiker haben hier mit Bewustsein weiter gebaut. Sie nemen jede einzelne Rechtssatzung, sie nehmen das Recht als solches in ihr Gesetzbuch hinein und verknüpfen alles mit der Autoritat Jabwes. Wie die Propheten Sittlichkeit, so haben die Deuteronomiker das Recht rcligios fundiert. Dadurch erste könnte das Recht eine für alle Fälle des Lebens massgebende Autorität werden, weil eben Jahwe dahinterstand: und Jus und Fas sind wieder, wie in ältester Zcit. in demselben religiösen Grund verankerl.

Sonder om die Skrifbeskouing van Herzberg te aanvaar, moet dit gestel word dat hierdie religieuse fundering van alle reg Bybels volledig korrek is .

Indien die reg vir burgerlike sake dan religieus gefundeer word en daar religieuse norme daarvoor deur God gegee word, hoe kan dit wees dat ander norme op die kerklike erf moet geld?

- Teokrasie

Juis omdat reg en geregtigheid so deel is van die wese van God is alle regspraak asof deur Homself. Norme kan dus nie verander volgens onderskeie tye, onderskeie terreine of onderskeie regeringstelsels nie. Daarom bring die feit dat ons vandag nie ' $n$ teokratiese bestel het soos in die Ou Testament nie, geen verandering aan die norme vir regspraak wat vir die staat of die kerk geld nie.

\section{$2.7 \quad$ Regspraak en sleutelmag}

Regspraak is nie die uitoefening van sleutelmag nie (contra GKSA, 1988:136). Wanneer tug uitgeoefen word, is reeds 'n regsbeslissing geneem. As een gelowige 'n ander tug, het hy reeds besluit dat die een wat getug word, gesondig het. Dieselfde geld van tug deur die kerkraad. Dis juis op grond van so 'n regsbeslissing dat tug uitgeoefen kan word wanneer dit gaan oor onreg wat geskied het. Die feit dat die sleutelmag gehanteer word deur 'n vergadering wil dus nog glad nie sê dat regspraak ook deur 'n vergadering, en dan ook dieselfde soort vergadering, moet geskied nie. Buitendien is Woordverkondiging deur die bedienaar van die Woord (as enkeling) en trouens deur elkeen in die amp van die gelowige die hantering van sleutelmag en is ook hierdie handeling nie noodwendig verbonde aan 'n vergadering nie.

Die Algemene Sinode van die Gereformeerde Kerke in Suidelike Afrika oordeel in 1988 in 'n antwoord op 'n beswaarskrif oor artikel 31 waarin dieselfde bepleit is as 
hier: "Die beswaarskrif is nie vanuit die Gereformeerde Kerkregeringstelsel soos o.a. uiteengesit in die Kerkorde en die NGB Artikels 30-32, beredeneer nie. Die basiese beginsel van die Gereformeerde Kerkregering is dat God sy Ryk (sic !) deur ouderlinge as raad regeer en nie deur enkelinge nie." (GKSA, 1988:136.) Hier word sonder enige besinning oorgegaan vanaf 'n regerende funksie na 'n regsprekende funksie vir dieselfde liggaam. Dit is juis die kern van die probleem: Dit is korrek dat die Here sy kerk presbiteriaal wil regeer, maar daar is geen aanduiding in die Skrif dat hierdie presbiteriale regeringsliggaam die funksie van regspraak moet usurpeer nie. Die teenoorgestelde is waar. Soos in die afdeling oor die Skrifbeginsels aangetoon. behoort regspraak deur onpartydige opgeleide persone of mense met besondere gawes daarvoor gedoen te word.

\subsection{Die Heilige Gees en gebed}

Dikwels word die argument gebruik dat hoewel dit so is dat die mense wat op 'n meerdere vergadering regspraak uitoefen nie altyd die saak verstaan nie, hulle tog deur die Heilige Gees gelei sal word om die regte beslissing te neem, want daarvoor het die vergadering en individue gebid. Dit is waar dat ondanks baie gebreke van mense die Here tog dikwels die goeie laat gebeur, maar dit grens aan onverantwoordelike optrede om met verbygaan van die norme wat die Here gegee het, te verwag dat die Heilige Gees die regte uitspraak moet gee. Daarom moet grondig besin word of Bybelse norme nog geld in die kerklike regspraak en of ander faktore nie in die plek daarvan gekom het nie.

\subsection{Die huidige praktyk in die Gereformeerde Kerke}

Die huidige praktyk in die Gereformeerde Kerke verloop soos volg: Wanneer iemand appelleer na 'n meerdere vergadering word die ontvanklikheid van die appèl behandel en indien dit voldoen aan die vereistes, kry die appellant en verweerder die geleentheid om hulle sake te stel. Daarna word die saak na 'n kommissie verwys om met 'n aanbeveling by die meerdere vergadering te kom. Hulle aanbeveling word dan deur die volle meerdere vergadering (gewoonlik met uitsondering van die deputate van die mindere vergadering teen wie geappelleer word) of aanvaar of verwerp of gewysig.

Dit is vanselfsprekend dat daar dikwels lede van 'n sinode is wat glad nie die regsaak waaroor hulle moet help beslis, verstaan nie. Op meerdere vergaderings word dit dikwels in die openbare vergadering of in die wandelgange erken. Selfs predikante erken dat hulle ook soms weens die gekompliseerdheid van regsake wat op die Nasionale Sinode van die Gereformeerde Kerke dien, dit nie kan verstaan nie. 
Juis omdat daar dan nie met verantwoordelikheid beslis kan word nie, word die gevaar van partydigheid sodoende groot. Daar word inderdaad 'n struikelblok voor diegene gelê wat moet deelneem aan regspraak as hulle 'n saak nie kan deurgrond nie en dan kan die beslissing maklik beïnvloed word deur persoonlike voorkeur.

Regspraak deur meerdere vergaderings het vroeg vanuit die demokrasie in die gereformeerde kerke van die Weste ingesluip en is geen Skriftuurlike beginsel nie. 'n Regter moet verantwoordelikheid dra vir sy regspraak soos gestel word in 2 Kronieke 19:6, Deuteronomium 1:17 en 16:20. Dis onmiddellik duidelik dat wanneer 'n stelsel iemand dwing om reg te spreek, soos in meerdere vergaderings, sonder dat die persoon wat regspreek in staat is om te verstaan wat hy doen, hy ook nie verantwoordelik kan wees vir sy regspraak nie. Verder is dit waar dat sodra 'n meerdere vergadering verdaag het na 'n regspraak die regter gesigloos geword het. Daardie meerdere vergadering sal nooit weer byeenkom nie en bestaan nie meer nie. Die Bybel bied nêrens 'n voorbeeld of 'n voorskrif van regspraak wat geskied op die wyse waarop dit deur meerdere vergaderings gedoen word nie.

\section{3. 'N MOONTLIKE ANDER WEG}

Dit sal beter wees as hierdie stelsel verander word sodat alleen mense wat bekwaam is kragtens gawes of opleiding, regspraak uitoefen. Daar is heelwat regsgeleerdes of persone wat 'n besondere gawe het vir regspraak in kerke en wat dit graag sal wil doen. 'n Klein groepie van enkele persone kan makliker en meer vaartbelynd as 'n meerdere vergadering die werk verrig. Regsake moet dikwels vir 'n lang tyd wag omdat meerdere vergaderings nie sommer maar net daarvoor opgeroep kan word nie. Op dié wyse moet mense soms lank onder onreg ly, terwyl die Here dit nie kan verdra nie. Enkele persone kan egter oor 'n naweek vergader en weer 'n volgende naweek voortgaan. Die beslissing van sulke regsdeputate kan nog steeds vir kennisname aan meerdere vergaderings gerapporteer word, maar slegs vir hulle kennisname. Elke meerdere vergadering kan regsdeputate vir die doel van regspraak benoem.

Artikel 31 Kerkorde kan moontlik soos volg gewysig word:

Wat op 'n kerklike vergadering met meerderheid van stemme besluit is, moet as vas en bindend beskou word tensy bewys word dat dit in stryd is met Gods Woord of die artikels van die Kerkorde. As iemand egter 'n klag het dat hy deur die uitspraak van 'n mindere vergadering of die regsdeputate van ' $n$ mindere vergadering veronreg is, $k a n$ hy hom beroep op die regsdeputate van ' $n$ meerdere vergadering. 
Om te beweer dat so 'n verandering nie toegelaat kan word nie omdat dit in stryd is met artikel 49 Kerkorde wat reël dat elke meerdere vergadering deputate benoem met 'n welomskrewe opdrag en dat hulle verslag moet doen aan die meerdere vergadering (GKSA, 1988:136) kan nie gehandhaaf word nie. Dis nog steeds deputate van die mindere of meerdere vergadering wat die werk verrig, hulle word nog steeds deur die vergadering benoem en hulle doen nog steeds verslag van hulle werk aan die betrokke vergadering. Dit berus ook steeds by die vergadering om hulle van hulle plig te onthef. Maar al sou dit in stryd wees met enige artikel van die Kerkorde is dit nie korrek om te redeneer dat wanneer 'n kerkorde-artikel in stryd is met die Skrif dit nie verander moet word nie, omdat die verandering in stryd is met 'n ander artikel van die Kerkorde. So-iets sou alleen beteken dat daardie ander artikel dan ook in stryd is met die Skrif.

\section{BIBLJOGRAITE}

CALVYN, J. 1949. Book of Psalms. (Transl. Anderson.) Grand Rapids : Ecrdmans.

ELOFF, T. 1988. Staatsowerheid en geregtigheid Met besondere verwysing na rasscklassifikasie. 'n Teologies-eticse studic. Pretoria (Procfskrif (D. Th.) - UP.)

GEREFORMEERDE KERK IN SUID-AFRIKA. 1979. Kerkorde van dic (iereformecrde Kerk in SuidAfrika soos gewysig deur verskillende sinodes. Potchefsiroom : Calyyn Jubileum Bockefonds.

GKSA

kyk

GEREFORMEERdE KERKE IN SUIDELIKE AFRIKA. 1988. Acta. Potchefstromm : Administratiewe Buro.

GISPEN, W.H. 1\%(X). S.v. Rechtspraak Christelijke Encyclopedic V. Kampen : Kok.

HERZBERG, H.W. 1923. Entwicklung des Begriffes MSPT im AT. ZATW, 41:16-76.

SPOELSTRA, B. 1989. Gereformeerde Kerkreg en kerkregering. 'n Handboek by die Kerkorde. Hammanskraal : Hammanskraalse Teologiese Skool van die Gereformeerde Kerke in SuidAfrika. 
